\title{
A phase II study of personalized peptide vaccination combined with gemcitabine for non-resectable pancreatic cancer patients
}

\author{
HIROAKI YANAGIMOTO ${ }^{1}$, HISANORI SHIOMI ${ }^{2}$, SOHEI SATOI ${ }^{1}$, TAKASHI MINE ${ }^{3}$, \\ HIDEYOSHI TOYOKAWA ${ }^{1}$, TOMOHISA YAMAMOTO ${ }^{1}$, TOHRU TANI ${ }^{2}$, AKIRA YAMADA $^{4}$, \\ A-HON KWON ${ }^{1}$, NOBUKAZU KOMATSU ${ }^{3}$, KYOGO ITOH ${ }^{3}$ and MASANORI NOGUCHI ${ }^{5}$
}

${ }^{1}$ Department of Surgery, Kansai Medical University, Hirakata; ${ }^{2}$ Department of Surgery, Shiga University of Medical Science, Ohtsu; ${ }^{3}$ Department of Immunology, ${ }^{4}$ Cancer Vaccine Division and ${ }^{5}$ Clinical Research Division of the Research Center for Innovative Cancer Therapy, Kurume University School of Medicine, Kurume, Japan

Received April 12, 2010; Accepted June 9, 2010

DOI: 10.3892/or_00000923

\begin{abstract}
We evaluated the safety of, and clinical and immune responses to personalized peptide vaccination with gemcitabine (GEM) as the first line therapy in patients with non-resectable pancreatic cancer. Pre-vaccination peripheral blood mononuclear cells (PBMCs) and plasma were prepared to examine cellular and humoral responses to 14 and 16 peptides in human leukocyte antigen (HLA)-A24+ or $-\mathrm{A} 2^{+}$ patients, respectively. Only the reactive peptides (maximum of 4) were administered weekly at $3 \mathrm{mg} /$ peptide. GEM was administered at $1000 \mathrm{mg} / \mathrm{m}^{2}$ per week for 3 weeks, followed by 1 week of rest. Twenty-one patients with untreated and non-resectable pancreatic cancer were enrolled. The combination therapy was generally well tolerated. Boosting of cellular and humoral responses to the vaccinated peptides was observed in the post-vaccination (eighth) PBMCs and plasma from 14 of 18 and 13 of 18 patients tested, respectively. The best clinical responses were 7 cases of partial response, 9 cases of stable disease, and 5 cases of progressive disease. Median survival time of all 21 patients was 9.0 months (95\% CI, 6-15.5 months) with a one year survival rate of $38 \%$. Immune boosting in both cellular and
\end{abstract}

Correspondence to: Dr Masanori Noguchi, Clinical Research Division of Research Center for Innovative Cancer Therapy, Kurume University School of Medicine, 67 Asahi-machi, Kurume 830-0011, Japan

E-mail: noguchi@med.kurume-u.ac.jp

Abbreviations: CTL, cytotoxic T lymphocytes; HLA, human leukocyte antigen; IFN- $\gamma$, interferon- $\gamma$; PBMC, peripheral blood mononuclear cells; GEM, gemcitabine; HIV, human immunodeficiency virus; EBV, Epstein-Barr virus; IgG, immunoglobulin G

Key words: pancreatic cancer, peptide vaccination, immunotherapy, gemcitabine humoral responses was well correlated with overall survival with a hazard ratio of 0.2 (95\% CI, 0.06-0.73; log-rank $\mathrm{p}=0.0239$ ). These results suggest a potential clinical benefit of this combination therapy for non-resectable pancreatic cancer patients as the first line therapy. Further exploration of this approach is warranted.

\section{Introduction}

Pancreatic cancer is the fourth largest cause of cancer death in the world. The median survival for all patients with pancreatic cancer does not exceed 2 years, with a 5-year survival rate of less than $20 \%$ (1). Gemcitabine (GEM) is currently the only drug approved by the US Food and Drug Administration for advanced stages of pancreatic cancer. However, in the pivotal study on which this approval was based, median survival was still less than 6 months (2), indicating the pressing need for the continued development of novel treatment strategies. Various combinations using GEM as a backbone have been designed and tested in clinical trials. Unfortunately, none of the combinations has been showing to be superior to GEM monotherapy.

Recent advances in tumor immunology have resulted in the identification of a number of antigens and their peptides that are recognized by tumor-reactive and human leukocyte antigen (HLA) class I-restricted cytotoxic T lymphocytes (CTL) (3). Cancer vaccines have emerged as a promising therapeutic approach (4), but their clinical responses have been limited (5). To overcome this limitation, we devised a new regime of peptide-based vaccination that consists of measuring pre-existing CTL precursors and IgG reactive to many kinds of vaccine candidate, followed by administration of the positively reactive peptides (personalized peptide vaccination) $(6,7)$. We then conducted a dose-escalation study of personalized peptide vaccination in combination with chemotherapy (8-10), including GEM, for advanced pancreatic cancer to increase clinical efficacy (10). Subsequently, we conducted a phase II study to investigate the clinical and immune responses of personalized peptide vaccination in combination with GEM for advanced pancreatic cancer patients as the first line therapy, and the results are reported herein. 


\section{Materials and methods}

Patients. The study protocol was approved by the institutional ethics review boards of Kansai Medical University and Shiga Medical University, and conducted in accordance with the Declaration of Helsinki. Complete written informed consent was obtained from all patients at the time of enrollment. Patients were included in the study if they were 18 years of age or older with HLA-A24+ and/or HLA-A2+ status as determined by commercially available serological tests (SRL, Japan), and had histologically or cytologically confirmed, locally advanced (non-resectable) or metastatic pancreatic adenocarcinoma. Patients had to exhibit an Eastern Cooperative Oncology Group (ECOG) performance status of $0-1$, no central nervous system metastases, and an expected survival of at least 3 months. The adequate hematologic, renal and hepatic functions required were: absolute neutrophil count $\geq 1500 / \mu 1$, lymphocyte count $\geq 1000 / \mu 1$, platelet count $\geq 100000 / \mu 1$, hemoglobin $\geq 8 \mathrm{~g} / \mathrm{dl}$, serum creatinine $<1.5 \mathrm{X}$ the upper limit of normal (ULN) value, alkaline phosphatase $<3 \mathrm{X}$ ULN value and bilirubin $<1.5 \mathrm{X}$ ULN value. Patients also had to be negative for hepatitis $\mathrm{B}$ and $\mathrm{C}$ antigens. Pregnant patients and those with autoimmune diseases or an active infection were excluded.

Study design and treatment. This was a non-randomized, openlabel, phase II study in patients with non-resectable pancreatic cancer. The treatment was carried out at Kansai Medical University Hospital and Shiga University Hospital. All immunological analyses were carried out at the Department of Immunology, Kurume University School of Medicine. All laboratory tests required to assess eligibility for entry had to be completed within 7 days prior to the start of treatment. The peptides utilized in the present study were prepared by Multiple Peptide Systems (San Diego, CA, USA) under the conditions of Good Manufacturing Practice. The peptide candidates consisted of SART2 ${ }_{93-101}, \mathrm{SART}_{161-169}, \mathrm{SART}_{109-118}$, $\mathrm{Lck}_{208-216}, \mathrm{Lck}_{486-494}, \mathrm{Lck}_{488-497}, \mathrm{MRP} 3_{503-511}, \mathrm{MRP}_{1293-1302}$, PAP $_{213-221}, \mathrm{PSA}_{248-257}, \mathrm{PSMA}_{624-624}, \mathrm{EZH}_{735-743}, \mathrm{EGF} \mathrm{R}_{800-809}$, and PTH-rP ${ }_{102-111}$ for patients with HLA-A24, and SART3 $3_{302-310}$, $\mathrm{SART3}_{309-317}, \mathrm{CypB}_{129-138}, \mathrm{Lck}_{246-254}, \mathrm{Lck}_{422-430}, \mathrm{ppMAPkkk}_{294-302}$, ppMAPkkk ${ }_{432-440}$, WHSC $_{103-111}$, WHSC $_{141-149}, \mathrm{UBE} \mathrm{V}_{43-51}$, UBE2 $_{\text {85-93 }}$, HNRPL $_{140-148}, \mathrm{HNRPL}_{501-510}, \mathrm{EZH}_{569-577}$, PSCA $_{21-30}$ and EGFR ${ }_{479-488}$ for patients with HLA-A2 (10). These peptides have the ability to induce HLA-A24- or -A2restricted and tumor-specific CTL activity in peripheral blood mononuclear cells (PBMCs) of cancer patients, and are frequently expressed in various tumor cell lines (7-10). The peptides were supplied in vials containing $3 \mathrm{mg} / \mathrm{ml}$ sterile solution for injection. Three milligrams of peptide with sterile saline was added in a 1:1 volume to the Monotide ISA-51 (Seppic, Paris, France), and then mixed in a Vortex mixer (Fisher, Alameda, CA, USA). The resulting emulsion (maximum of 4 peptides per vaccination) was injected subcutaneously into the femoral area, once a week for 8 weeks. GEM $\left(1000 \mathrm{mg} / \mathrm{m}^{2}\right)$ was administered as a 30 -min intravenous infusion once a week for 3 weeks, followed by 1 week of rest. That is, 1 cycle of treatment consisted of 8 vaccinations and 6 GEM administrations over an 8 -week period. The cycle was repeated every 8 weeks as long as the patients agreed to continue and their condition was considered appropriate for vaccination. Toxicity was evaluated in patients who received $>4$ vaccinations, while both immunological and clinical evaluations were conducted in those who received $>8$ vaccinations. Blood samples for studies of immune responses were obtained on weeks 0,4 and 8 during Cycle 1 and then every 2 months for a total of 2 years. In cases of Grade 3/4 neutropenia or Grade 2/3 thrombocytopenia, the GEM dose was reduced by $20 \%$. Patient therapy was discontinued in the event of Grade 3/4 neutropenia complicated by fever (i.e., febrile neutropenia); Grade 4 neutropenia lasting longer than 4 days; Grade 4 thrombocytopenia; any Grade 3/4 nonhaematological toxicity except anorexia, and nausea and vomiting in the absence of appropriate antiemetics; and a delay in recovery from treatment-related toxicity of $>2$ weeks.

Measuring of peptide-specific CTL precursors. Thirty milliliters of peripheral blood was obtained before and after the eighth vaccination, and PBMCs were isolated by FicollConray density gradient centrifugation. Peptide-specific CTL precursors in PBMCs were detected using a previously reported culture method (11). Briefly, PBMCs (1x105 cells/ well) were incubated with $10 \mu \mathrm{M}$ of a peptide in $200 \mu \mathrm{l}$ of culture medium in u-bottom-type 96-well microculture plates (Nunc, Roskilde, Denmark). The culture medium consisted of $45 \%$ RPMI-1640 medium, 45\% AIM-V medium (Gibco BRL), $10 \% \mathrm{FCS}, 100 \mathrm{U} / \mathrm{ml}$ of interleukin-2 (IL-2) and $0.1 \mu \mathrm{M}$ MEM non-essential amino acid solution (Gibco BRL). Half of the medium was removed and replaced with a new medium containing a corresponding peptide $(20 \mu \mathrm{M})$ every 3 days. After incubation for 14 days, these cells were harvested and tested for their ability to produce IFN- $\gamma$ in response to CIR-A2402 (kindly provided by Dr M. Takiguchi, Kumamoto University, Japan) or T2 cells that were pre-loaded with either a corresponding peptide or HIV peptides (RYLRQQLLGI for HLA-A24 and LLFGYPVYV for HLA-A2) as a negative control. The level of IFN- $\gamma$ was determined by enzyme-linked immunosorbent assay (ELISA) (limit of sensitivity: $10 \mathrm{pg} / \mathrm{ml}$ ). All assays were performed in quadruplicate. A two-tailed Student's t-test was employed for the statistical analyses. A well was considered positive when the level of IFN- $\gamma$ production in response to a corresponding peptide was significantly higher $(\mathrm{p}<0.05)$ than that in response to an HIV peptide, and when the mean amount of IFN- $\gamma$ production in response to a corresponding peptide was $>50 \mathrm{ng} / \mathrm{ml}$ compared with that in response to an HIV peptide. Increment of CTL activity was judged as positive if the post-vaccination sample, but not the pre-vaccination sample, showed CTL activity. It was also judged as positive if the level of IFN- $\gamma$ produced by the postvaccination (eighth) sample was two times higher than that by the pre-vaccination sample

Measuring of peptide-specific IgG. The levels of anti-peptide immunoglobulin $\mathrm{G}$ ( $\mathrm{IgG}$ ) were measured using the Luminex ${ }^{\mathrm{TM}}$ system, as previously reported (12). In brief, plasma was incubated with $25 \mu 1$ of peptide-coupled color-coded beads for $2 \mathrm{~h}$ at room temperature on a plate shaker. After incubation, the mixture was washed with a vacuum manifold apparatus and incubated with $100 \mu 1$ of biotinylated goat anti-human 
Table I. Baseline patient characteristics $(n=21)$.

\begin{tabular}{|c|c|c|}
\hline Characteristics & No. & $(\%)$ \\
\hline \multicolumn{3}{|l|}{ Age (years) } \\
\hline Median & \multicolumn{2}{|c|}{64} \\
\hline Range & \multicolumn{2}{|c|}{$48-80$} \\
\hline \multicolumn{3}{|l|}{ Gender } \\
\hline Male & 13 & 62 \\
\hline Female & 8 & 38 \\
\hline \multicolumn{3}{|l|}{ Performance status (ECOG) } \\
\hline 0 & 14 & 67 \\
\hline 1 & 7 & 33 \\
\hline \multicolumn{3}{|l|}{ HLA typing } \\
\hline A-2 & 7 & 33 \\
\hline A-24 & 9 & 43 \\
\hline A-2 and -24 & 5 & 24 \\
\hline \multicolumn{3}{|l|}{ Stage at study entry } \\
\hline IVa & 4 & 19 \\
\hline $\mathrm{IVb}$ & 17 & 81 \\
\hline \multicolumn{3}{|l|}{ Primary site } \\
\hline Head & 6 & 29 \\
\hline Body & 4 & 19 \\
\hline Tail & 5 & 24 \\
\hline Head and body & 2 & 9 \\
\hline Body and tail & 4 & 19 \\
\hline \multicolumn{3}{|l|}{ Metastatic site } \\
\hline None & 4 & 19 \\
\hline Liver & 7 & 33 \\
\hline Lymph node & 2 & 10 \\
\hline Lung & 2 & 10 \\
\hline Liver and lymph node & 5 & 24 \\
\hline Lymph node and bone & 1 & 4 \\
\hline
\end{tabular}

ECOG, Eastern Cooperative Oncology Group; HLA, human leucocyte antigen.

IgG (chain-specific) for $1 \mathrm{~h}$ at room temperature. The plate was then washed, followed by the addition of $100 \mu \mathrm{l}$ of streptavidin-PE into wells, and was incubated for $30 \mathrm{~min}$ at room temperature on a plate shaker. The bound beads were washed three times followed by the addition of $100 \mu \mathrm{l}$ of Tween-PBS into each well. Fifty microliters of sample was detected using the Luminex ${ }^{\mathrm{TM}}$ system. The limit of sensitivity of this assay was 10 fluorescence intensity units (FIU) as reported previously (12). Post-vaccination (eighth) plasma FIU values $>1.5$ times those of pre-vaccination plasma were considered as elevated.

Adverse events and clinical responses. Adverse events were monitored according to the National Cancer Institute Common Terminology Criteria for Adverse Events version 3.0. The clinical response was evaluated based on clinical observations and radiological findings. All known sites of disease were evaluated on a monthly basis by computed tomography (CT) scan or magnetic resonance imaging (MRI) examination
Table II. Treatment-related adverse events.

\begin{tabular}{lrrrrrr}
\hline & \multicolumn{7}{c}{ Grade (no. of patients) } & & \\
\cline { 2 - 5 } Toxicity & 1 & 2 & 3 & 4 & $\begin{array}{r}\text { All } \\
(\%)\end{array}$ & $\begin{array}{c}\text { Grade } \\
\text { Hematological }\end{array}$ \\
\cline { 2 - 5 } Neutropenia & 0 & 5 & 7 & 1 & 62 & 38 \\
Anemia & 9 & 8 & 4 & 0 & 100 & 19 \\
Thrombocytopenia & 8 & 3 & 1 & 0 & 57 & 5 \\
Non-hematological & & & & & & \\
Nausea/vomiting & 8 & 3 & 0 & 0 & 52 & 0 \\
Diarrhea & 3 & 0 & 0 & 0 & 14 & 0 \\
Stomatitis & 2 & 3 & 0 & 0 & 24 & 0 \\
Anorexia & 4 & 12 & 0 & 0 & 76 & 0 \\
Fatigue & 6 & 8 & 0 & 0 & 67 & 0 \\
Fever & 6 & 0 & 0 & 0 & 29 & 0 \\
Rash & 1 & 2 & 0 & 0 & 14 & 0 \\
Alopecia & 5 & 0 & 0 & 0 & 24 & 0 \\
Hyper bilirubenia & 3 & 0 & 0 & 0 & 14 & 0 \\
Increased AST/ALT & 13 & 4 & 2 & 0 & 90 & 10 \\
Increased creatinine & 1 & 1 & 0 & 0 & 10 & 0 \\
Taste alteration & 7 & 2 & 0 & 0 & 43 & 0 \\
Dermatologic reactions & 5 & 11 & 0 & 0 & 76 & 0 \\
\hline AST & & & & & & \\
\hline
\end{tabular}

AST, aspartate aminotransferase; ALT, alanine aminotransferase.

before and after each cycle. The tumor size was estimated via direct measurement of the region of abnormal enhancement observed by CT scan or MRI examination. Patients were assigned a response category according to the Response Evaluation Criteria in Solid Tumors (RECIST).

Statistical methods. The primary end-points in this study were 1-year survival rate and overall survival. A single-stage design was used for testing hypotheses about the true 1-year survival rate. For each indication, $p_{0}$ was defined as the survival rate at or below which this combination therapy would be considered ineffective or clinically unimportant, and $p_{1}$ was defined as the minimum survival rate that would merit further clinical development. For this study, $p_{0}$ and $p_{1}$ were set at the survival rates of 10 and $30 \%$, respectively. The $\alpha$ and $\beta$ error rates were set at 0.05 and 0.20 , respectively. On the basis of these estimates, the required sample sizes were 21 evaluable patients. Secondary end-points included characterization of toxicities and immune responses to this treatment. Time to event end-point and 1-year survival were derived by the Kaplan-Meier method. The relationship between survival and pretreatment factors was analyzed using the log-rank test with a two-sided significance level of $5 \%$.

\section{Results}

Patient characteristics. A total of 21 patients were enrolled in the study between September 2006 and March 2008. Data were collected until April 2009. Seventeen (81\%) patients with stage IVb had metastatic disease and 4 patients (19\%) with stage IVa had locally advanced pancreatic cancer 
Table III. Immune response during the treatment.

\begin{tabular}{|c|c|c|c|c|c|c|c|c|c|c|c|c|}
\hline \multirow[b]{2}{*}{$\begin{array}{l}\text { Patient } \\
\text { no. }\end{array}$} & \multirow[b]{2}{*}{$\begin{array}{l}\text { No. of } \\
\text { GEM }\end{array}$} & \multirow[b]{2}{*}{$\begin{array}{c}\text { No. of } \\
\text { vaccination }\end{array}$} & \multirow[b]{2}{*}{ Peptide } & \multicolumn{3}{|c|}{$\begin{array}{l}\text { Anti-peptide } \\
\text { cellular response }\end{array}$} & \multicolumn{3}{|c|}{$\begin{array}{l}\text { Anti-peptide } \\
\text { IgG response }\end{array}$} & \multirow[b]{2}{*}{$\begin{array}{l}\text { Best clinical } \\
\text { response }\end{array}$} & \multirow[b]{2}{*}{$\begin{array}{c}\text { Follow-up } \\
\text { (months) }\end{array}$} & \multirow[b]{2}{*}{ Prognosis } \\
\hline & & & & Pre & $\begin{array}{l}\text { Post } \\
\text { (eighth) }\end{array}$ & $\begin{array}{l}\text { Increased } \\
\text { response }\end{array}$ & Pre & $\begin{array}{c}\text { Post } \\
\text { (eighth) }\end{array}$ & $\begin{array}{l}\text { Increased } \\
\text { response }\end{array}$ & & & \\
\hline \multirow[t]{3}{*}{1} & 16 & 21 & SART3 109-118 & 0 & 0 & - & 536 & 4645 & + & SD & 8 & Dead \\
\hline & & & Lck 486-494 & 0 & 0 & - & 62 & 69 & - & & & \\
\hline & & & MRP3 1293-1302 & 0 & 0 & - & 152 & 183 & - & & & \\
\hline \multirow[t]{4}{*}{2} & 3 & 4 & SART3 109-118 & 0 & NA & NA & 21 & NA & NA & PD & 3 & Dead \\
\hline & & & Lck 486-494 & 0 & NA & NA & 81 & NA & NA & & & \\
\hline & & & Lck 488-497 & 0 & NA & NA & 16 & NA & NA & & & \\
\hline & & & MRP3 1293-1302 & 0 & NA & NA & 19 & NA & NA & & & \\
\hline \multirow[t]{3}{*}{3} & 12 & 13 & SART3 109-118 & 0 & 2500 & + & 151 & 753 & + & SD & 6 & Dead \\
\hline & & & Lck 486-494 & 0 & 77 & + & 125 & 221 & + & & & \\
\hline & & & MRP3 1293-1302 & 1436 & 0 & - & 13 & 10 & - & & & \\
\hline \multirow[t]{3}{*}{4} & 17 & 22 & SART3 109-118 & 0 & 352 & + & 268 & 1296 & + & $\mathrm{SD}$ & 9.5 & Dead \\
\hline & & & Lck 486-494 & 0 & 452 & + & 12 & 10 & - & & & \\
\hline & & & MRP3 1293-1302 & 0 & 0 & - & 199 & 800 & + & & & \\
\hline \multirow[t]{2}{*}{5} & 9 & 11 & SART3 109-118 & 0 & 0 & - & 168 & 1647 & + & $\mathrm{PD}$ & 4.5 & Dead \\
\hline & & & Lck 486-494 & 120 & 0 & - & 17 & 34 & + & & & \\
\hline \multirow[t]{4}{*}{6} & 33 & 25 & SART3 109-118 & 0 & 1215 & + & 381 & 6259 & + & PR & 15.5 & Dead \\
\hline & & & Lck 486-494 & 413 & 0 & - & 213 & 41 & - & & & \\
\hline & & & Lck 488-497 & 0 & 1250 & + & 29 & 34 & - & & & \\
\hline & & & MRP3 1293-1302 & 995 & 0 & - & 16 & 20 & - & & & \\
\hline \multirow[t]{4}{*}{7} & 26 & 25 & SART2 93-101 & 136 & 0 & - & 139 & 287 & + & PR & 11 & Dead \\
\hline & & & SART2 161-169 & 0 & 0 & - & 116 & 162 & - & & & \\
\hline & & & SART3 109-118 & 0 & 151 & + & 174 & 331 & + & & & \\
\hline & & & Lck 488-497 & 0 & 1000 & + & 125 & 221 & + & & & \\
\hline 8 & 16 & 23 & SART2 93-101 & 0 & 0 & - & 70 & 266 & + & $\mathrm{SD}$ & 18 & Alive \\
\hline & & & SART2 161-169 & 0 & 0 & - & 76 & 148 & + & & & \\
\hline & & & SART3 109-118 & 0 & 108 & + & 835 & 730 & - & & & \\
\hline & & & Lck 488-497 & 0 & 73 & + & 111 & 130 & - & & & \\
\hline 9 & 20 & 23 & UBE2V 43-51 & 0 & 115 & + & 218 & 220 & - & PR & 7 & Dead \\
\hline & & & PSCA 21-30 & 0 & 960 & + & 90 & 85 & - & & & \\
\hline & & & EZH2 569-577 & 0 & 196 & + & 16 & 16 & - & & & \\
\hline & & & EGFR 479-488 & 0 & 80 & + & 26 & 20 & - & & & \\
\hline 10 & 8 & 9 & SART3 302-310 & 0 & 450 & + & 1099 & 1803 & + & $\mathrm{SD}$ & 24 & Alive \\
\hline & & & SART3 309-317 & 0 & 0 & - & 42 & 67 & + & & & \\
\hline & & & Lck 246-254 & 1350 & 0 & - & 10 & 10 & - & & & \\
\hline & & & UBE2V 43-51 & 0 & 550 & + & 29 & 24 & - & & & \\
\hline 11 & 13 & 20 & СурВ 129-138 & 0 & 0 & - & 10 & 10 & - & PR & 5 & Dead \\
\hline & & & Lck 246-254 & 0 & 0 & - & 27 & 14 & - & & & \\
\hline & & & WHSC2 141-149 & 799 & 0 & - & 10 & 10 & - & & & \\
\hline 12 & 42 & 34 & SART3 302-310 & 0 & 780 & + & 4423 & 6247 & - & PR & 23 & Alive \\
\hline & & & СурВ 129-138 & 0 & 60 & + & 4489 & 5718 & - & & & \\
\hline & & & HNRPL 501-510 & 0 & 0 & - & 775 & 1134 & - & & & \\
\hline & & & UBE2V 43-51 & 587 & 99 & - & 2788 & 4101 & + & & & \\
\hline 13 & 26 & 24 & SART3 309-317 & 0 & 55 & + & 143 & 128 & - & PR & 14 & Dead \\
\hline & & & СурВ 129-138 & 0 & 0 & - & 49 & 44 & - & & & \\
\hline & & & WHSC2 103-111 & 0 & 0 & - & 63 & 49 & - & & & \\
\hline & & & UBE2V 43-51 & 0 & 62 & + & 4548 & 10068 & + & & & \\
\hline 14 & 25 & 23 & СурВ 129-138 & 0 & 0 & - & 16 & 100 & + & PR & 12.5 & Alive \\
\hline & & & UBE2V 43-51 & 0 & 1725 & + & 235 & 265 & - & & & \\
\hline 15 & 15 & 17 & SART3 109-118 & 92 & 0 & - & 74 & 80 & - & $\mathrm{SD}$ & 8 & Dead \\
\hline & & & Lck 486-494 & 0 & 0 & - & 30 & 35 & - & & & \\
\hline & & & MAP 432-440 & 0 & 3058 & + & 10 & 10 & - & & & \\
\hline & & & UBE2V 43-51 & 0 & 0 & - & 24 & 32 & - & & & \\
\hline
\end{tabular}


Table III. Continued.

\begin{tabular}{|c|c|c|c|c|c|c|c|c|c|c|c|c|}
\hline \multirow[b]{2}{*}{$\begin{array}{l}\text { Patient } \\
\text { no. }\end{array}$} & \multirow[b]{2}{*}{$\begin{array}{l}\text { No. of } \\
\text { GEM }\end{array}$} & \multirow[b]{2}{*}{$\begin{array}{c}\text { No. of } \\
\text { vaccination }\end{array}$} & \multirow[b]{2}{*}{ Peptide } & \multicolumn{3}{|c|}{$\begin{array}{l}\text { Anti-peptide } \\
\text { cellular response }\end{array}$} & \multicolumn{3}{|c|}{$\begin{array}{l}\text { Anti-peptide } \\
\text { IgG response }{ }^{\mathrm{b}}\end{array}$} & \multirow[b]{2}{*}{$\begin{array}{l}\text { Best clinical } \\
\text { response }\end{array}$} & \multirow[b]{2}{*}{$\begin{array}{c}\text { Follow-up } \\
\text { (months) }\end{array}$} & \multirow[b]{2}{*}{ Prognosis } \\
\hline & & & & Pre & $\begin{array}{l}\text { Post } \\
\text { (eighth) }\end{array}$ & $\begin{array}{c}\text { Increased } \\
\text { response }\end{array}$ & Pre & $\begin{array}{l}\text { Post } \\
\text { (eighth) }\end{array}$ & $\begin{array}{l}\text { Increased } \\
\text { response }\end{array}$ & & & \\
\hline \multirow[t]{4}{*}{16} & 7 & 17 & SART3 109-118 & 0 & 0 & - & 67 & 76 & - & SD & 6 & Dead \\
\hline & & & Lck $422-430$ & 0 & 0 & - & 10 & 10 & - & & & \\
\hline & & & СурВ 129-138 & 0 & 962 & + & 58 & 81 & - & & & \\
\hline & & & WHSC2 103-111 & 0 & 0 & - & 24 & 31 & - & & & \\
\hline \multirow[t]{4}{*}{17} & 8 & 9 & SART3 109-118 & 53 & 51 & - & 99 & 91 & - & SD & 9 & Dead \\
\hline & & & SART3 302-310 & 0 & 0 & - & 129 & 590 & + & & & \\
\hline & & & UBE2V 43-51 & 0 & 0 & - & 117 & 79 & - & & & \\
\hline & & & HNRPL 501-510 & 0 & 0 & - & 113 & 79 & - & & & \\
\hline \multirow[t]{4}{*}{18} & 6 & 8 & SART3 109-118 & 457 & NA & NA & 299 & NA & NA & PD & 4.5 & Dead \\
\hline & & & Lck 488-497 & 0 & NA & NA & 72 & NA & NA & & & \\
\hline & & & UBE2V 43-51 & 0 & NA & NA & 498 & NA & NA & & & \\
\hline & & & HNRPL 501-510 & 0 & NA & NA & 100 & NA & NA & & & \\
\hline \multirow[t]{4}{*}{19} & 4 & 8 & SART3 109-118 & 0 & NA & NA & 73 & NA & NA & PD & 3 & Dead \\
\hline & & & UBE2V 43-51 & 63 & NA & NA & 71 & NA & NA & & & \\
\hline & & & WHSC2 103-111 & 0 & NA & NA & 10 & NA & NA & & & \\
\hline & & & WHSC2 141-149 & 0 & NA & NA & 10 & NA & NA & & & \\
\hline \multirow[t]{4}{*}{20} & 12 & 16 & SART3 109-118 & 0 & 0 & - & 120 & 123 & - & PD & 12 & Alive \\
\hline & & & Lck 488-497 & 0 & 0 & - & 232 & 291 & - & & & \\
\hline & & & SART3 309-317 & 0 & 61 & + & 161 & 197 & - & & & \\
\hline & & & UBE2V 43-51 & 0 & 50 & + & 531 & 638 & - & & & \\
\hline \multirow[t]{4}{*}{21} & 17 & 24 & SART3 109-118 & 0 & 0 & - & 323 & 576 & + & SD & 12 & Alive \\
\hline & & & Lck 486-494 & 0 & 0 & - & 163 & 209 & - & & & \\
\hline & & & Lck 488-497 & 132 & 100 & - & 118 & 171 & - & & & \\
\hline & & & 1PTHrP 102-111 & 0 & 75 & + & 180 & 127 & - & & & \\
\hline
\end{tabular}

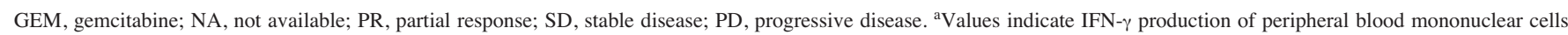
(PBMCs) reactive to the corresponding peptide (pg/ml). A two-tailed Student's t-test was employed for the statistical analyses. A well was considered positive when the level of IFN- $\gamma$ production in response to a corresponding peptide was significantly higher $(\mathrm{p}<0.05)$ than that in response to an HIV peptide, and also when the mean amount of IFN- $\gamma$ production in response to a corresponding peptide was $>50 \mathrm{ng} / \mathrm{ml}$ compared with that to an HIV peptide. Increment of CTL activity was judged as positive if the post-vaccination sample, but not the pre-vaccination sample, showed CTL activity. It was also judged as positive if the level of IFN- $\gamma$ produced by the post-vaccination sample was $>2$ times higher

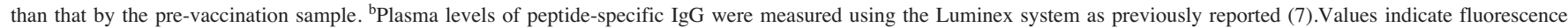
intensity units (FIU) of IgG antibodies reactive to the corresponding peptide. Post-vaccination plasma values $>1.5$ times those of pre-vaccination plasma were considered as elevated.

without distant metastasis. No patients had received any prior therapy. Eighteen of 21 patients $(86 \%)$ had an elevated serum CA 19-9 level (>2X ULM). Median follow-up time was 9.0 months (range, 3-24 months). Patient characteristics are listed in Table I.

Treatment administration. Patients received a median of 15 doses of GEM (range, 3-42) and a median of 20 vaccinations (range, 4-34). Nineteen patients $(90 \%)$ received at least $>6$ doses of GEM and 8 vaccinations (one cycle). Two patients discontinued study treatment before completing one cycle because of objective evidence of disease progression. For the selection of peptides for the first to the eighth vaccination (the first cycle), pre-vaccination plasma was provided to investigate reactivity to each of the 14 or 12 peptides in the HLA-A $24^{+}$patients $(n=9)$ or HLA-A2 ${ }^{+}$patients $(n=7)$, respectively, followed by selection of the 4 peptides at maximum with the higher levels of IgG reactive to each of the peptides in order. To the HLA-A $24^{+}$and $-\mathrm{A} 2^{+}$patients $(n=5)$, all 26 peptides were provided for the selection of peptides followed by selection of the 2 peptides from 14 peptides for HLA-A24+ patients and the remaining 2 peptides from 12 peptides for HLA-A2+ patients with the higher levels of $\mathrm{IgG}$ reactive to each of the peptides in order. A summary of the administered peptides is shown in Table III. For the second cycle (ninth to sixteenth), the 4 peptides at maximum were similarly chosen for the administration on the basis of the results of screening of both PBMCs and plasma. The same process used in the second cycle was repeated for patients who entered the third cycle.

Toxicity. Significant toxicities (Grade 3/4) were predominantly hematologic in nature, with the most common, neutropenia (Table II), considered to be caused by GEM itself. No occurrences of febrile neutropenia were recorded during the course of our study. Grade 3/4 anemia and thrombo- 
$\mathbf{A}$

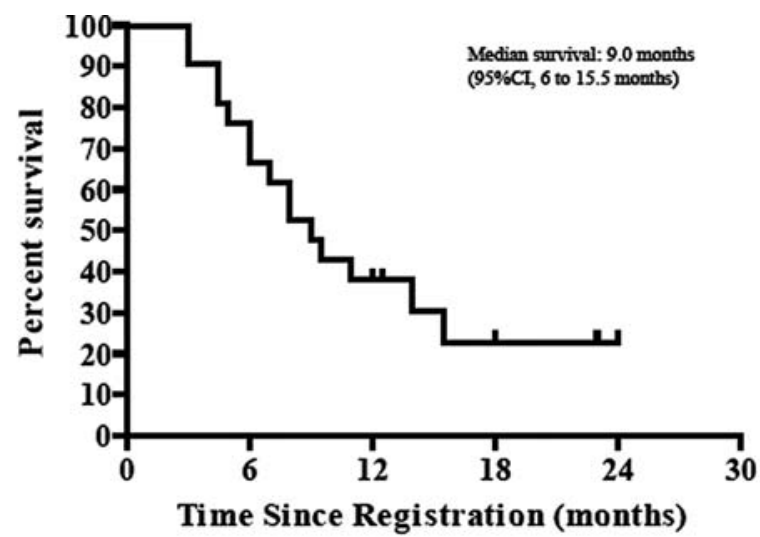

No. of patients at risk:

$\begin{array}{lllll}21 & 16 & 8 & 3 & 1\end{array}$

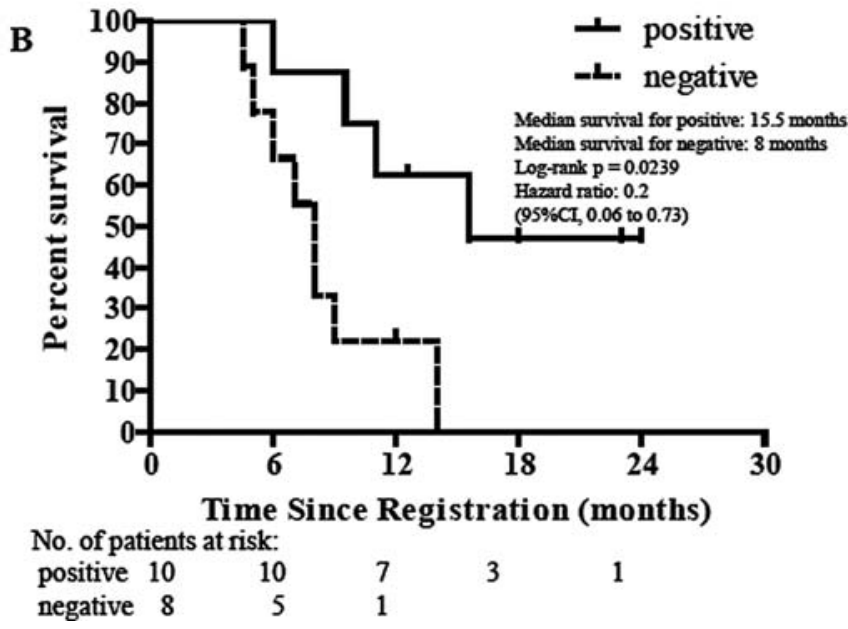

Figure 1. (A) Overall survival, (B) overall survival according to immune response.

cytopenia occurred infrequently. Most of these hematologic toxicities were transient and reversible. Grade 3/4 nonhematologic toxicities were rare and included two instances of liver function abnormalities. In addition, $79 \%$ of the patients had only Grade $1 / 2$ dermatologic reactions at the vaccination site. These results indicated that this protocol was generally well tolerated. Details of adverse events are presented in Table II.

Immune responses. Peptide-specific cellular and humoral immune activities were measured at 8-week intervals for as long as patient samples were available. The peptides used for vaccination and the corresponding immune responses are described in Table III. Three patients (nos. 2, 18 and 19) were not eligible owing to rapid progression before taking the sample. Among the 18 patients tested, the augmentation of peptide-specific CTL responses in post-eighth-vaccination PBMCs by INF- $\gamma$ production was observed in 14 patients, and the augmentation of IgG responses in post-eighth-vaccination plasma was also observed in 13 patients. Boosting of both CTL and $\mathrm{IgG}$ responses was observed in 10 of 18 patients $(56 \%)$ tested. CTL or IgG responses to $>2$ peptides were observed in 10 of $18(56 \%)$ and 5 of $18(28 \%)$ tested patients, respectively.
Clinical responses and correlation to the immune responses. All clinical responses were confirmed by an independent review, and were as follows: 7 PR (33\%), 9 SD (43\%) and 5 PD (24\%). The disease control rate was $76 \%$. Before treatment, the levels of CA 19-9 were elevated (>2X ULM) in 18 of 21 patients. In these 18 patients, the levels decreased $\geq 50 \%$ and $<50 \%$ compared with those before treatment in 7 $(33 \%)$ and $4(19 \%)$ patients after the treatment, respectively. For all 21 patients, the Kaplan-Meier method was used to calculate median time to progression (TTP) at 7.0 months (95\% CI, 3-9 months) and median overall survival at 9.0 months (95\% CI, 6-15.5 months). At the time of this analysis, 5 patients are still alive, and the 1-year survival rate was $38 \%$ (Fig. 1A). In addition, we analyzed overall survival in 18 patients tested according to the immune response, in which boosting in both CTL and IgG responses at the eighth vaccination was defined as positive (Fig. 1B). Patients with a positive immune response had a significantly better prognosis than those with a negative response. The median overall survival was 15.5 months in positive patients and 8 months in negative patients with a hazard ratio of 0.2 (95\% CI, 0.060.73; log-rank $\mathrm{p}=0.0239$ ).

\section{Discussion}

Single-agent GEM remains the standard chemotherapy regime for advanced pancreatic cancer patients on the basis of a phase III clinical study demonstrating that GEM is superior to fluorouracil, and exhibited a modest effect on survival and a favorable impact on quality of life (2). In that study, the median survival and 1-year survival rate were 5.7 months and $18 \%$, respectively. So far, the current targeted agents that have been used in combination with GEM have failed to improve clinical outcome (13). For instance, several phase III studies have evaluated the combination of GEM and a cytotoxic agent or a vaccine in patients with advanced pancreatic cancer. Heinemann et al conducted a multicenter phase III trial that randomly assigned 198 patients to receive either GEM alone or in combination with cisplatin (14). Improvements were seen for the combination arm in terms of TTP (4.6 vs. 2.5 months, $\mathrm{p}=0.016)$ and rate of disease control (70.2 vs. $49 \%, \mathrm{p}<0.001)$, but there was no survival benefit of the combination (7.6 vs. 6.0 months, $\mathrm{p}=0.12$ ). Another phase III trial to compare GEM with or without oxaliplatin showed a benefit only in progression-free survival but not overall survival (15). Telomerase-derived peptide vaccination (GV1001) showed a median overall survival of 8.6 months in non-resectable pancreatic cancer (16). In order to compare the efficacy of a combination therapy of GV1001 and GEM with that of GEM monotherapy, a phase III trial was designed (17). Unfortunately, after 365 patients were enrolled, a preliminary analysis indicated no survival benefit of GV1001.

Our combination therapy of personalized peptide vaccination with GEM relies on immunological responses, suggesting that optimal anti-tumor activity may result from less immune suppression in combination with GEM. Our previous study, a dose-escalation phase I study for combination therapy of personalized peptide vaccination with GEM in patients with advanced pancreatic cancer, demonstrated that GEM does not inhibit the immune responses induced by personalized 
peptide vaccination. In this study, increases in cellular or humoral responses specific to vaccinated peptides were observed in the post-vaccination (eighth) samples of 12 of 13 patients with the disease control rate (PR plus SD) of $69 \%$ and MST of 7.6 months, and the recommended dose of each peptide was $3 \mathrm{mg}$ (10). Subsequently, we conducted the present study to evaluate the efficacy and toxicity of combination therapy of personalized peptide vaccination with GEM for patients with non-resectable pancreatic cancer as a first line treatment. Although this study was a small phase II study, this combination therapy was found to produce a relatively good response rate of $67 \%$. In addition, the median TTP of 7.0 months and median overall survival of 9.0 months were better than those reported in most studies of GEM monotherapy or other combination therapies for advanced pancreatic cancer.

The safety profile of GEM plus personalized peptide vaccination was consistent with those seen in studies of GEM monotherapy, suggesting that personalized peptide vaccination can be combined safely with a standard dose of GEM. The non-overlapping toxicity profiles of the two drugs permit maximum benefit to be derived from each without significantly affecting patient safety. Significant toxicities (Grade 3/4) were predominantly hematologic in nature, with neutropenia being most common.

There were no episodes of neutropenic fever, no significant bleeding episodes and no treatment-related deaths. Furthermore, there were no non-hematological toxicities including dermatologic skin reaction at the vaccination injection, nausea and anorexia were manageable, and no unexpected occurrence. Therefore, the combination of personalized peptide vaccination with GEM used according to our schedule appears to be tolerable in patients with advanced pancreatic cancer.

In the present study, among the 18 patients tested, augmentation of peptide-specific CTL responses in the post-eighthvaccination PBMCs by INF- $\gamma$ production was observed in 14 patients, and augmentation of IgG responses in the posteighth-vaccination plasma was also observed in 13 patients. These results are consistent with our previous observation that a standard dose of GEM did not inhibit the immune responses induced by personalized peptide vaccination (10). Moreover, immune boosting in both cellular and humoral responses was well correlated with overall survival with a hazard ratio of 0.2 (95\% CI, 0.06-0.73; log-rank $\mathrm{p}=0.0239)$. These results suggest that both cellular and humoral responses are needed to obtain clinical benefits under this combined therapy. Further studies with a large number of patients are needed to confirm this.

In conclusion, this protocol of personalized peptide vaccine with GEM was well tolerated. It is noteworthy that both cellular and humoral responses to the immunizing peptides were observed in the vast majority of patients, regardless of whether they had received a standard dose of GEM. In view of these findings, the survival benefit in comparison with GEM alone needs to be confirmed in future clinical studies.

\section{Acknowledgements}

This study was supported in part by Grants-in-Aid (KAKENHI) (no.12213134 to K.I.), 'TOSHI aria jigyo to Kurume City', and by 'High-Tech Research Center' Project for Private Universities: matching fund subsidy from Ministry of Education, Culture, Sports, Science and Technology (MEXT) of Japan.

\section{References}

1. Li D, Xie K, Wolff R and Abbruzzes JL: Pancreatic cancer. Lancet 363: 1049-1059, 2004.

2. Burris HA III, Moore MJ, Andersen J, et al: Improvements in survival and clinical benefit with gemcitabine as first-line therapy for patients with advanced pancreas cancer: a randomized trial. J Clin Oncol 15: 2403-2413, 1997.

3. Novellino L, Castelli C and Parmiani G: A listing of human tumor antigens recognized by T cells: March 2004 update. Cancer Immuno Immunother 54: 187-207, 2005.

4. Rosenberg SA: A new era for cancer immunotherapy based on the genes that encode cancer antigens. Immunity 10: 281-287, 1999.

5. Rosenberg SA, Yang JC and Rastifo NP: Cancer immunotherapy: moving beyond current vaccines. Nat Med 10: 909-915, 2004.

6. Noguchi M, Kobayashi K, Suetsugu N, et al: Induction of cellular and humoral immune responses to tumor cells and peptides in HLA-A24 positive hormone-refractory prostate cancer patients by peptide vaccination. Prostate 57: 80-92, 2003.

7. Mine T, Sato Y, Noguchi M, et al: Humoral responses to peptides correlate with overall survival in advanced cancer patients vaccinated with peptides based on pre-existing peptide-specific cellular responses. Clin Cancer Res 10: 929937, 2004

8. Noguchi M, Itoh K, Yao A, et al: Immunological evaluation of individualized peptide vaccination with a low-dose of estramustine for HLA-A24 ${ }^{+}$HRPC patients. Prostate 63: 1-12, 2005.

9. Sato Y, Fujiwara T, Mine T, et al: Immunological evaluation of personalized peptide vaccination in combination with a 5fluorouracil derivative (TS-1) for advanced gastric or colorectal carcinoma patients. Cancer Sci 98: 1113-1119, 2007.

10. Yanagimoto $\mathrm{H}$, Mine $\mathrm{T}$, Yamamoto $\mathrm{K}$, et al: Immunological evaluation of personalized peptide vaccination with gemcitabine for pancreatic cancer. Cancer Sci 98: 605-611, 2007.

11. Hida N, Maeda Y, Katagiri K, Takasu H, Harada M and Itoh K: A simple culture protocol to detect peptide-specific cytotoxic T lymphocyte precursors in circulation. Cancer Immunol Immunotherapy 51: 219-228, 2002.

12. Komatsu N, Shichijo S, Nakagawa M and Itoh K: New multiplexed flow cytometric assay to measure anti-peptide antibody: a novel tool for monitoring immune responses to peptides used for immunization. Scand J Cin Lab Invest 64: 1-11, 2004.

13. Li J and Saif MW: Any progress in the management of advanced pancreatic cancer? J Pancreas 10: 361-365, 2009.

14. Heinemann V, Quietzsch D, Gieseler F, et al: Randomized phase III trial of gemcitabine plus cisplatin compared with gemcitabine alone in advanced pancreatic cancer. J Clin Oncol 24: 3946-3952, 2006

15. Louvet C, Labianca R, Hammel P, et al: Gemcitabine in combination with oxaliplatin compared with gemcitabine in locally advanced or metastatic pancreatic cancer: results of a GERCOR and GISCAD phase III trial. J Clin Oncol 23: 3509-3516, 2005.

16. Bernhardt SL, Gjertsen MK, Trachsel S, et al: Telomerase peptide vaccination of patients with non-resectable pancreatic cancer: a dose escalating phase I/II study. Br J Cancer 95: 1474-1482, 2006.

17. Buanes T, Maurel J, Liauw W, Hebbar M and Nemunaitis J: A randomized phase III study of gemcitabine $(\mathrm{G})$ versus GV1001 in sequential combination with $\mathrm{G}$ in patients with unresectable and metastatic pancreatic cancer (PC). J Clin Oncol 27 (Suppl. 15): abs. 4601, 2009. 